\title{
Pembelajaran Blended Learning Sosio Antropologi Olahraga untuk Mahasiswa Pendidikan Jasmani dan Kesehatan
}

\author{
Hafidz Gusdiyanto ${ }^{1}$, Wasis Djoko Dwiyogo ${ }^{1}$, Sapto Adi ${ }^{1}$ \\ ${ }^{1}$ Pendidikan Olahraga-Universitas Negeri Malang
}

\begin{tabular}{l} 
INFO ARTIKEL \\
\hline Riwayat Artikel: \\
Diterima: 03-05-2019 \\
Disetujui: $13-01-2020$ \\
\hline
\end{tabular}

Kata kunci:

socio anthropology;

blended learning;

physical education and health

sciences,

sosio antropologi

blended learning;

pendidikan jasmani dan kesehatan

\begin{abstract}
ABSTRAK
Abstract: The purpose of this research and development is (1) to produce a learning product based on blended learning (face-to-face, offline, and online) in sports socio antropology subjects, (2) as well as testing the effectiveness, efficiency, and attractiveness of development products produced in learning outcomes. The results of the study obtained the following data: (1) small group trials obtained an (89.11\%), (2) large group trials obtained an (88.96\%). The effectiveness test carried out three times obtained the overall average results of $(85.05 \%)$ with a very complete category. Efficiency tests obtained data, namely (1) meeting I obtained an average time (01:09:47), (2) meeting II obtained an average time (1:04:39), (3) meeting III obtained an average average time (00:56:37), when compared with the amount of time used by lecturers by $2 \times 50$ minutes then there has been time efficiency in the learning process. The results of the attraction test of product attractiveness were obtained from three meetings through questionnaires: (1) face to face the results were $(92.29 \%)$, (2) in offline the results obtained at (94.43\%), (3) at online obtained results of (94.43\%) with very attractive categories.
\end{abstract}

\begin{abstract}
Abstrak: Tujuan penelitian dan pengembangan ini yaitu (1) menghasilkan sebuah produk pembelajaran Sosio Antropologi Olahraga berbasis blended learning (tatap muka, offline, online) dan (2) menguji efektivitas, efisiensi, dan daya tarik produk pengembangan. Hasil penelitian diperoleh data (1) hasil uji coba kelompok kecil diperoleh rata-rata $89,11 \%$, (2) hasil uji coba kelompok besar diperoleh rata-rata $88,96 \%$. Uji efektivitas yang dilaksanakan sebanyak tiga kali diperoleh hasil rata-rata keseluruhan $(85,05 \%)$ dengan kategori sangat tuntas. Uji efisiensi diperoleh data yaitu: (1) pertemuan I diperoleh rata-rata waktu (01:09:47), (2) pertemuan II diperoleh ratarata waktu (01:04:39), (3) pertemuan III diperoleh rata-rata waktu (00:56:37), jika dibandingkan dengan jumlah waktu yang digunakan dosen pengampu sebesar $2 \times 50$ menit maka telah terjadi efisien waktu pada proses pembelajaran. Hasil uji daya tarik kemenarikan produk diperoleh dari tiga kali pertemuan melalui penyebaran angket (1) pertemuan tatap muka diperoleh hasil sebesar $92,29 \%$, (2) pertemuan offline diperoleh hasil sebesar $94,43 \%$, dan (3) pertemuan online diperoleh hasil sebesar $94,43 \%$ dengan kategori sangat menarik.
\end{abstract}

\section{Alamat Korespondensi:}

Hafidz Gusdiyanto

Pendidikan Olahraga

Universitas Negeri Malang

Jalan Semarang 5 Malang

E-mail: hafidgusdiyanto@gmail.com

Di abad 21 saat ini perkembangan teknologi informasi dan komunikasi sangat cepat sehingga menimbulkan beberapa perubahan di dalam kehidupan bermasyarakat. Pemanfaatan teknologi juga terjadi di dunia pendidikan karena pendidikan di masa depan akan berubah arah yaitu lebih bersifat fleksibel dan dapat diakses oleh siapapun dan dimanapun bagi siapa saja yang memerlukan. Di dalam proses pembelajaran ketercapaian hasil belajar sangat diperlukan. Untuk mencapai ketercapaian belajar ada beberapa unsur yang memengaruhi. Unsur yang memengaruhi, yaitu unsur pendidik/dosen, peserta didik/mahasiswa, kurikulum serta sarana dan prasarana yang mendukung di dalam proses pembelajaran. Saat ini proses pembelajaran kebanyakan masih menggunakan model pembelajaran tradisional, efek yang ditimbulkan dari pembelajaran tradisional yaitu banyaknya peserta didik yang pasif dan kurang kreatif pada saat proses pembelajaran. Dengan menggabungkan teknologi dan media pembelajaran yang menarik, maka sistem pendidikan di masa datang akan lebih terbuka dan minat peserta didik terhadap proses pembelajaran semakin meningkat dan dapat dilakukan dimanapun dan kapanpun. 
Untuk meningkatkan hasil belajar yang maksimal harus melalui proses pembelajaran dengan pemilihan motode pembelajaran dan media pembelajaran yang tepat. Penggunaan metode dan media pembelajaran yang tepat dan sesuai kebutuhan peserta didik akan membatu pendidik di dalam proses pembelajaran sehingga kegiatan pembelajaran sesuai dengan tujuan pembelajaran yang ingin dicapai. Usaha yang di maksud yaitu terkait dengan pemanfaatan teknologi di dalam proses pembelajaran. Menurut (Vernadakis, Giannousi, Derri, Michalopoulos, \& Kioumourtzoglou, 2012) dalam penelitiannya menyimpulkan bahwa penelitian teknologi dalam pembelajaran menarik minat dan respek siswa terhadap proses pembelajaran jika dibandingkan dengan pembelajaran konvensional. Selain itu, penggunaan teknologi dalam pembelajaran mcmiliki efek yang positif dan terbukti efektif terhadap harapan dan basil belajar siswa. Menurut (Saba, 2009) penerapan teknologi di dalam dunia pendidikan merupakan sebuah perubahan persepsi belajar dari teacher center ke student center dan pembelajaran yang dulunya kaku menjadi lebih fleksibel.

Sosio Antropologi Olahraga adalah salah satu ilmu yang diajarkan di perguruan tinggi Fakultas Ilmu Keolahragaan yang mempelajari budaya dan sejarah awal mula terjadinya interaksi-interaksi di dalam dunia olahraga. Di dalam matakuliah Sosio Antropologi Olahraga peserta didik dibekali bagaimana melihat olahraga dari sudut pandang yang berbeda. Sudut pandang tersebut yaitu melihat olahraga dari masyarakat langsung dan sejarah mulai terbentuknya olahraga. Perkembangan ilmu pengetahuan dan teknologi semakin berkembang cepat pada abad 21. Penggunaan teknologi saat materi pemberian materi kepada peserta didik dapat mengeksplorasi materi yang lebih baik dibandingkan dengan metode pembelajaran tatap muka saja (Berlex, 2008) (Sharma, 2011). Salah satu media pembelajaran yang berfungsi untuk pembelajaran dan hasil belajar pemecahan masalah adalah blended learning. (Dwiyogo, 2016) (Sutopo, 2012) (Mazoloumiyan, Shobeiri, Farajollahi, \& Mohamadi, 2012) (Vaughan, 2014) menjelaskan bahwa blended learning adalah pembelajaran yang mengombinasikan strategi penyampaian pembelajaran menggunakan kegiatan tatap muka, pembelajaran berbasis komputer (offline), dan komputer secara online (internet dan mobile learning). Tujuan utama dari pembelajaran blended learning adalah memberikan kesempatan bagi pebelajar agar terjadi pembelajaran yang mandiri, menarik, efektif, dan efisien (Reigeluth, 2012). Terdapat kelebihan dan kekurangan di dalam Blended learning. (Dwiyogo, 2016) menyatakan keuntungan pembelajaran blended learning, yaitu (1) memperluas jangkauan pembelajaran/pelatihan, (2) kemudahan implementasi, (3) efisien biaya, (4) hasil yang optimal, (5) menyesuaikan kebutuhan pebelajar, (6) meningkatkan daya tarik pembelajaran. Model pembelajaran blended learning juga memiliki kekurangan. Kekurangan pada pembelajaran blended learning, yaitu (1) media yang dibutuhkan sangat beragam, sehingga sulit diterapkan apabila sarana dan prasarana tidak mendukung, (2) tidak meratanya fasilitas yang dimiliki pelajar, seperti komputer dan akses internet, dan (3) kurangnya pengetahuan masyarakat terhadap penggunaan teknologi.

Hasil analisis kebutuhan menggunakan penyebaran angket yang dilakukan terhadap 40 mahasiswa Pendidikan Jasmani dan Kesehatan Universitas Negeri Malang pada September 2018 diperoleh hasil (1) 41,25\% menjawab materi sosio antropologi olahraga tidak ada hambatan dan 58,75\% ada hambatan selama pembelajaran matakuliah Sosio Antropologi Olahraga, (2) 80\% mengatakan sangat dibutuhkan bahan ajar dalam matakuliah Sosio Antropologi Olahraga dan 10\% membutuhkan serta 10\% kurang membutuhkan, (3) 60\% sangat bermanfaat jika dikembangkan bahan ajar yang berbasis blended learning dan $20 \%$ bermanfaat serta $20 \%$ kurang bermanfaat, (4) $80 \%$ sangat setuju dikembangkan pembelajaran Sosio Antropologi Olahraga yang dikemas menggunakan bahan ajar berbasis blended learning dan $10 \%$ setuju serta $10 \%$ kurang setuju.

Pembelajaran Sosio Antropologi Olahraga menggunakan metode blended learning yang diterapkan terhadap mahasiswa pendidikan jasmani dan kesehatan menggunakan tiga media pembelajaran, yaitu tatap muka (face to face), offline, dan online. Pada pembelajaran tatap muka menggunakan buku ajar untuk menyampaikan dan menjelaskan materi di kelas, pada saat pembelajaran offline akan menggunakan aplikasi autoplay media studio 8.0 yang dapat diakses mahasiswa di laptop, dan pada pembelajaran online menggunakan kelas virtual edmodo. Peneliti menggunakan ketiga media tersebut setelah melakukan analisis kebutuhan, agar media yang digunakan sesuai kebutuhan mahasiswa dan dosen serta dapat bermanfaat dalam proses pembelajaran. Penggunaan media pembelajaran Sosio Antropologi Olahraga yang dilakukan dan dikemas menggunakan media blended learning diharapkan dapat bermanfaat untuk mahasiswa dan dosen Pendidikan Jasmani dan Kesehatan serta penggunaan teknologi dalam dunia pendidikan diharapkan dapat membawa pembaharuan dalam proses pembelajaran.

\section{METODE}

Pengembangan pembelajaran Sosio Antropologi Olahraga berbasis blended learning untuk mahasiswa Pendidikan Jasmani dan Kesehatan Universitas Negeri Malang ini berpedoman rancangan pembelajaran yang berbasis blended learning (Dwiyogo, 2016). Tahapan model pembelajaran blended leaning, meliputi (1) analisis kebutuhan pemecahan masalah, (2) identifikasi dari sumber belajar serta kendala, (3) identifikasi karakteristik pebelajar, (4) menetapkan tujuan dari pembelajaran, (5) memilih serta menetapkan strategi pembelajaran, (6) mengembangkan sumber, (7) uji coba, (8) revisi, dan (9) prototipe rancangan pembelajaran Sosio Antropologi Olahraga berbasis blended learning untuk mahasiswa Pendidikan Jasmani dan Kesehatan Universitas Negeri Malang.

Penelitian dan pengembangan menggunakan penelitian kuantitatif dengan metode pre-experimental design. (Sugiyono, 2016) mengelompokkan tiga jenis design penelitian yang familiar untuk digunakan pada metode pre-experimental design, yaitu one shot case study, one group pretest-posttest design, and intact-group comparison. Desain one-shot case study yang dipilih oleh peneliti karena sesuai dengan kebutuhan. One-shot case study merupakan salah satu desain penelitian yang subjek penelitian hanya satu kelompok yang diberi perlakuan kemudian hasil yang diperoleh dianalisis lebih lanjut. 
Teknik analisis data dalam penelitian yang digunakan adalah teknik analisis data kualitatif dan kuantitatif. Hasil belajar dari peserta didik dapat diketahui melalui tiga indikator, yaitu (1) keefektifan, (2) efisiensi, dan (3) daya tarik pembelajaran (Degeng, 2013). Indikator efektivitas bertujuan untuk menetapkan keefektifan hasil dari proses pembelajaran. Efisiensi pembelajaran mengukur efisiensi pembelajaran, indikatornya mengacu pada waktu, personalia, dan sumber belajar yang dipakai. Daya tarik pembelajaran sebagai hasil pembelajaran, erat sekali kaitan dengan daya tarik produk pembelajaran. Hasil akhir dilihat dari hasil ketuntasan minimal unjuk kerja yang telah dicapai dirumuskan dalam rumus persentase menurut (Akbar, 2013) sebagai berikut.

$$
V=\frac{\mathrm{TSEV}}{\mathrm{S}-\max } \times 100 \%
$$

\section{Keterangan:}

$\mathrm{V}$

TSEV

$\mathrm{S}-\max$

$100 \%$
= Validitas

$=$ Total skor empirik validator

= Skor maksimal yang diharapkan

= Konstanta

Apabila datanya berupa persentase, maka kesimpulan dapat diambil disesuaikan dengan permasalahnnya (Akbar, 2013). Adapun penggolongan persentase yang dimaksud sebagaimana pada tabel 1 .

Tabel 1. Penggolongan Presentase Pengolahan Data

\begin{tabular}{|c|c|c|c|}
\hline No & Persentase & Kategori & Keterangan \\
\hline 1 & $81,00-100,00 \%$ & Sangat Valid, sangat efektif, sangat tuntas Cukup valid & Dapat digunakan tanpa perbaikan \\
\hline 2 & $61,00-80,00 \%$ & Cukup valid, cukup efektif, cukup tuntas & Dapat digunakan namun perlu perbaikan kecil \\
\hline 3 & $41,00-60,00 \%$ & Kurang Valid, kurang efektif atau kurang tuntas & $\begin{array}{l}\text { Perlu perbaikan besar, disarankan tidak } \\
\text { digunakan }\end{array}$ \\
\hline 5 & $00,00-20,00 \%$ & Sangat Tidak Valid, sangat tidak efektif, sangat tidak tuntas & Tidak bisa digunakan \\
\hline
\end{tabular}

Sumber: (Akbar, 2013)

Di dalam penelitian ini hanya ada satu subjek penelitian. Subjek tersebut akan mendapatkan perlakuan dengan penggunaan produk pengembangan pembelajaran. Di akhir pemberian perlakuan, subjek diberikan tes menggunakan produk pembelajaran yang dikembangkan dan pengisian angket untuk mengetahui hasil yang dibutuhkan yang dijealskan pada tabel 2 .

Tabel 2. Uji Efektivitas Menggunakan One Shot Case Study

\begin{tabular}{lll}
\hline \multicolumn{1}{c}{ Subjek } & \multicolumn{1}{c}{ Perlakuan (X) } & \multicolumn{1}{c}{ Observasi (O) } \\
\hline Mahasiswa Pendidikan Jasmani dan & Penerapan pembelajaran Sosio Antropologi Olahraga untuk & Hasil diperoleh dari hasil uji \\
$\begin{array}{l}\text { Kesehatan Universitas Negeri Malang } \\
\text { yang berjumlah 35 mahasiswa }\end{array}$ & mahasiswa Pendidikan Jasmani dan Kesehatan Universitas Negeri & $\begin{array}{l}\text { efektivitas, efisiensi, dan } \\
\text { daya tarik produk }\end{array}$ \\
\hline
\end{tabular}

\section{HASIL}

Berikut ini dijelaskan hasil dari analisis kebutuhan, uji validasi ahli, dan uji coba kelompok yang terdiri dari temuan data kualitatif dan data kuantitatif, selengkapnya dapat dilihat pada tabel 3.

\section{Analisis Data Uji Efektivitas, Efisiensi, dan Daya Tarik Kemenarikan Produk}

Hasil uji efektivitas menunjukkan dari tiga kali pertemuan tatap muka, offline, dan online diperoleh kesimpulan bahwa setelah melakukan uji efektivitas terhadap 35 mahasiswa Pendidikan Jasmani dan Kesehatan mengalami perkembangan dan peningkatan selama menerapkan proses pembelajaran sosio antropologi olahraga berbasis blended learning dari aspek keefektifan, efisiensi, dan daya tarik pembelajaran. Data hasil keseluruhan disajikan pada tabel 4. 
Tabel 3. Penyajian Data Keseluruhan

\begin{tabular}{|c|c|c|}
\hline No & Komponen & Hasil Temuan \\
\hline \multirow[t]{2}{*}{1} & $\begin{array}{l}\text { Analisis Kebutuhan } \\
\text { a. Analisis kebutuhan menggunakan } \\
\text { angket mahasiswa pendidikan jasmani } \\
\text { dan kesehatan Universitas Negeri } \\
\text { Malang sebanyak } 35 \text { mahasiswa }\end{array}$ & $\begin{array}{l}\text { Mahasiswa masih merasa sulit memahami materi yang dijelaskan dosen } \\
\text { Mahasiswa menggunakan sumber belajar untuk mendukung proses } \\
\text { pembelajaran dengan laptop dan smartphone yang mereka punya } \\
>\quad \text { Media pembelajaran yang digunakan dosen hanya buku dan powerpoint } \\
\text { Mahasiswa menjawab belum pernah mendengar tentang model } \\
\text { pembelajaran berbasis blended learning } \\
\text { Mahasiswa menjawab sangat setuju jika dikembangkan bahan ajar } \\
\text { pembelajaran Sosio Antropologi Olahraga berbasis blended learning. }\end{array}$ \\
\hline & $\begin{array}{l}\text { b. Hasil analisis kebutuhan dengan dosen } \\
\text { matakuliah sosio antropologi olahraga } \\
\text { pendidikan jasmani dan kesehatan } \\
\text { Universitas Negeri Malang }\end{array}$ & $\begin{array}{l}\text { Bahan ajar yang digunakan dalam proses pembelajaran Sosio Antropologi } \\
\text { Olahraga masih minim dan terakhir terbit pada tahun } 2001 \\
\text { Perlu dimanfaatkannya media pembelajaran yang menarik dalam } \\
\text { pembelajaran sosio antropologi olahraga. } \\
\text { belum pernah menerapkan blended learning pada pembelajaran Sosio } \\
\text { Antropologi Olahraga. }\end{array}$ \\
\hline \multirow[t]{3}{*}{2} & $\begin{array}{l}\text { Validasi Ahli } \\
\text { a. Validasi Ahli Pembelajaran yang } \\
\text { dilaksanakan pada bulan Maret } 2019 \\
\text { dengan instrumen angket sebanyak } 32 \\
\text { butir pertanyaan }\end{array}$ & $\begin{array}{l}\text { Dari hasil validasi ahli pembelajaran yang terdiri dari } 32 \text { pertanyaan } \\
\text { didapatkan hasil } 92,97 \% \text { yang termasuk dalam kategori sangat valid. } \\
\text { Masukan dan saran dari ahli pembelajaran adalah upayakan video } \\
\text { pembelajaran diberi narasi agar lebih menarik. }\end{array}$ \\
\hline & $\begin{array}{l}\text { b. Validasi Ahli Materi Sosio } \\
\text { Antropologi Olahraga yang } \\
\text { dilaksanakan pada bulan Maret } 2019 \\
\text { dengan instrumen angket sebanyak } 32 \\
\text { butir pertanyaan }\end{array}$ & $\begin{array}{l}\text { Dari hasil validasi ahli materi Sosio Antropologi Olahraga yang terdiri dari } \\
32 \text { pertanyaan didapatkan hasil } 92,97 \% \text { yang termasuk dalam kategori } \\
\text { sangat valid. } \\
\text { Masukan dan saran dari ahli materi Sosio Antropologi Olahraga adalah (1) } \\
\text { Materi pada bab III tentang materi proses sosial dan interaksi sosial dalam } \\
\text { olahraga ditambah (2) pada video pembelajaran tambahkan narasi } \\
\text { penjelasan materi. }\end{array}$ \\
\hline & $\begin{array}{l}\text { c. Validasi Ahli Media yang } \\
\text { dilaksanakan pada bulan Maret } 2019 \\
\text { dengan instrumen angket sebanyak } 29 \\
\text { pertanyaan }\end{array}$ & $\begin{array}{l}\text { Dari hasil validasi ahli media yang terdiri dari } 29 \text { pertanyaan didapatkan hasil } \\
\text { 93,10\% yang termasuk dalam kategori sangat valid. } \\
\text { Masukan dan saran dari ahli media adalah (1) gunakan font standart teks untuk } \\
\text { sajian materi pembelajaran, (2) transisi dalam video dibuat lebih smooth, dan (3) } \\
\text { cantumkan rujukan dalam daftar rujukan di media pembelajaran. }\end{array}$ \\
\hline 3 & $\begin{array}{l}\text { Uji Coba } \\
\text { a. Uji coba kelompok kecil yang } \\
\text { dilaksanakan pada bulan Maret } 2019 \\
\text { pada mahasiswa Pendidikan Jasmani } \\
\text { dan Kesehatan Universitas Negeri } \\
\text { Malang }\end{array}$ & $\begin{array}{l}\text { Dari hasil uji coba kelompok kecil untuk mengetahui kelayakan produk, untuk } \\
\text { kriteria kejelasan dan kesesuaian diperoleh persentase sebesar } 91 \% \text {, untuk kriteria } \\
\text { keefektifan diperoleh persentase sebesar } 88,61 \% \text {, untuk kriteria kemudahan } \\
\text { diperoleh kemudahan diperoleh persentase sebesar } 87,67 \% \text {, dan untuk kriteria } \\
\text { kemenarikan diperoleh persentase sebesar } 89,17 \% \text {. } \\
\text { Dari rata-rata keseluruhan diperoleh persentase sebesar } 89,11 \% \text { dengan kriteria } \\
\text { sangat valid sehingga dapat dijadikan acuan untuk melanjutkan ketahap selanjutnya } \\
\text { yaitu uji coba kelompok besar }\end{array}$ \\
\hline & $\begin{array}{l}\text { b. Uji coba kelompok besar yang } \\
\text { dilaksanakan pada bulan Maret } 2019 \\
\text { pada mahasiswa Pendidikan Jasmani } \\
\text { dan Kesehatan Universitas Negeri } \\
\text { Malang }\end{array}$ & $\begin{array}{l}\text { Dari hasil uji coba kelompok besar untuk mengetahui kelayakan produk, untuk } \\
\text { kejelasan dan kesesuaian diperoleh persentase sebesar } 88,86 \% \text {, untuk kriteria } \\
\text { keefektifan diperoleh persentase sebesar } 89,17 \% \text {, untuk kriteria kemudahan diperoleh } \\
\text { kemudahan diperoleh persentase sebesar } 88,71 \% \text {, dan untuk kriteria kemenarikan } \\
\text { diperoleh persentase sebesar } 89,11 \% \text {. } \\
\text { Dari rata-rata keseluruhan diperoleh persentase sebesar } 88,96 \% \text { dengan kriteria sangat } \\
\text { valid sehingga diperoleh produk pengembangan pembelajaran Sosio Antropologi } \\
\text { Olahraga menggunakan blended learning dan dapat dilanjutkan ketahap selanjutnya } \\
\text { yaitu uji efektivitas, efisiensi, dan daya tarik produk. }\end{array}$ \\
\hline
\end{tabular}


Tabel 4. Uji Efektivitas, Efisiensi, dan Daya Tarik

\begin{tabular}{|c|c|c|}
\hline No & Komponen & Hasil \\
\hline 1 & Efektivitas & $\begin{array}{l}\text { Hasil efektivitas didapatkan hasil } \\
\text { Nilai yang diperoleh mahasiswa pada pertemuan pertama untuk materi bab II, III dan IV diperoleh hasil nilai sebagai } \\
\text { berikut: (1) nilai terendah } 70 \text { kredit } \mathrm{B},(2) \text { nilai tertinggi } 100 \text { kredit A, dan (3) keseluruhan nilai diperoleh rata-rata } \\
82,38 \text { kredit A-. } \\
\text { Nilai yang diperoleh mahasiswa pada pertemuan kedua untuk materi bab V, VI, dan VII diperoleh nilai sebagai beikut: } \\
\text { (1) nilai terendah } 70 \text { kredit } \mathrm{B},(2) \text { nilai tertinggi } 100 \text { kredit } \mathrm{A} \text {, dan (3) keseluruhan nilai diperoleh rata-rata } 83,90 \text { kredit } \\
\text { A-. } \\
\text { Nilai yang diperoleh mahasiswa pada pertemuan ketiga untuk materi bab VII dan IX diperoleh nilai sebagai berikut: } \\
\text { (1) nilai terendah } 75 \text { kredit B+, (2) nilai tertinggi } 100 \text { kredit A, dan (3) keseluruhan nilai diperoleh rata-rata } 85 \text { kredit } \\
\text { A. } \\
\text { Setiap pertemuan diperoleh peningkatan nilai, yaitu (1) pada pertemuan pertama ke pertemuan kedua mengalami } \\
\text { peningkatan } 1,52 \%,(2) \text { pada pertemuan kedua ke pertemuan ketiga mengalami peningkatan } 1,10 \% \text {. Rata keseluruan } \\
\text { dari semua pertemuan dengan hasil nilai } 90,29 \text { kredit A. Menurut panduan Universitas Negeri Malang sekurang- } \\
\text { kurangnya nilai } 59 \text { atau C masih dikategorikan tuntas atau diakui kreditnya sehingga dari data yang diperoleh } \\
\text { mahasiswa dikatakan tuntas. }\end{array}$ \\
\hline 2 & Efisiensi & $\begin{array}{l}\text { Hasil uji efisiensi didapatkan hasil. } \\
\text { Waktu yang dibutuhkan mahasiswa pada pertemuan pertama menggunakan pembelajaran metode tatap muka untuk } \\
\text { materi bab } 2 \text {, bab } 3 \text { dan bab } 4 \text { diperoleh waktu terlama } 01.18 .15 \text { atau satu jam delapan belas menit lima belas detik dan } \\
\text { waktu tercepat } 00.58 .05 \text { atau lima puluh delapan menit lima detik. } \\
\text { Waktu yang dibutuhkan mahasiswa pertemuan kedua menggunakan pembelajaran metode offline dengan materi pada } \\
\text { bab } 5 \text {, bab } 6 \text { dan bab } 7 \text { diperoleh rata-rata waktu terlama } 01.07 .15 \text { atau satu jam tujuh menit lima belas detik dan waktu } \\
\text { tercepat } 00.57 .37 \text { atau lima puluh tujuh menit tiga puluh tujuh detik. } \\
\text { Waktu yang dibutuhkan mahasiswa pertemuan ketiga pembelajaran metode online pada materi bab } 8 \text { dan bab } 9 \\
\text { diperoleh rata-rata waktu terlama } 01.01 .40 \text { atau satu jam satu menit empat puluh detik dan waktu tercepat } 00.51 .00 \\
\text { atau lima puluh satu menit. } \\
\text { Jumlah waktu yang diperoleh pada setiap mahasiswa dalam tiga kali pertemuan diperoleh waktu yang terlama } 03.22 .50 \\
\text { atau tiga jam dua puluh dua menit lima puluh sembilan detik dan waktu tercepat } 02.51 .04 \text { atau dua jam lima puluh satu } \\
\text { menit empat detik. } \\
\text { Setiap pertemuan diperoleh efisiensi waktu, yaitu (1) antara pertemuan pertama dengan pertemuan kedua diperoleh } \\
\text { selisih waktu 0.05.07 atau lima menit tujuh detik, (2) antara pertemuan kedua dengan pertemuan ketiga diperoleh } \\
\text { 0.08.02 atau delapan menit dua detik. Jika dibandingkan dengan waktu yang digunakan oleh dosen pengampu } \\
\text { matakuliah Sosio Antropologi Olahraga } 2 x 50 \text { menit, maka dapat disimpulkan terdapat efisiensi waktu yang diperoleh } \\
\text { dalam mempelajari materi serta mengerjakan soal evaluasi di dalam setiap pertemuan. }\end{array}$ \\
\hline 3 & Daya Tarik & $\begin{array}{l}\text { Berdasarkan hasil uji daya tarik produk belajar maka diperoleh hasil dari tiga kali pertemuan melalui penyebaran } \\
\text { angket yang terdiri dari } 15 \text { butir pertanyaan: (1) pada pertemuan I (tatap muka) diperoleh hasil sebesar } 92,29 \%,(2) \\
\text { pada pertemuan II (offline) diperoleh hasil sebesar 94,43\%, (3) pada pertemuan III (online) diperoleh hasil sebesar } \\
94,43 \% \text {. Menurut (Akbar, 2013) dengan presentase 75.01-100.00\% dengan kriteria sangat menarik dan produk } \\
\text { tersebut digunakan tanpa revisi. } \\
\text { Berdasarkan hasil data tersebut maka dapat disimpulkan dengan menggunakan produk pengembangan matakuliah } \\
\text { sosio antropologi olahraga berbasis blended learning dapat mengalami peningkatan selama proses perlakuan yang } \\
\text { diberikan, mulai terdiri dari efektivitas, efisiensi, dan daya tarik terhadap produk pembelajaran. }\end{array}$ \\
\hline
\end{tabular}

\section{PEMBAHASAN}

Setelah melalui tahapan-tahapan yang telah dijelaskan terkait dengan penelitian dan pengembangan pembelajaran sosio antropologi olahraga berbasis blended learning dalam upaya meningkatkan hasil belajar mahasiswa. Berdasarkan pernyataan tersbeut, maka produk yang dihasilkan terdiri dari tiga produk pembelajaran sebagai media pembelajaran, yaitu (1) bahan ajar pembelajaran tatap muka (buku cetak), (2) bahan ajar pembelajaran offline (multimedia interaktif/autoplay), dan (3) bahan ajar pembelajaran online (edmodo). Dari berdasarkan hasil uji kelayakan diperoleh hasil (1) kriteria kejelasan dan kesesuaian diperoleh persentase sebesar 88,86\%, (2) kriteria keefektifan diperoleh presentase sebesar 89,17\%, (3) kriteria kemudahan diperoleh persentase sebesar 88,71\% dengan kategori, dan (4) kriteria kemenarikan diperoleh persentase sebesar $89,11 \%$. Secara keseluruhan, diperoleh persentase sebesar $88,96 \%$ dengan kategori sangat valid sehingga diperoleh produk pengembangan bahan ajar pembelajaran Sosio Antropologi Olahraga yang siap digunakan. Produk yang telah siap digunakan memiliki kelebihan, yaitu (1) buku ajar pembelajaran Sosio Antropologi Olahraga dilengkapi dengan QR Barcode berbasis blended learning belum ada di jurusan Pendidikan Jasmani dan Kesehatan, (2) pembelajaran sosio antropologi olahraga dengan menggunakan multimedia interaktif dan edmodo sebagai alternatif sumber belajar mampu meningkatkan motivasi dan hasil belajar mahasiswa, dan (3) memberikan referensi tambahan bagi mahasiswa dan dosen dalam memahami materi-materi pembelajaran Sosio Antropologi Olahraga. 
Pada produk bahan ajar pembelajaran Sosio Antropologi Olahraga berbasis blended learning terbagi atas tiga produk pembelajaran, yaitu (1) buku cetak pembelajaran Sosio Antropologi Olahraga, (2) multimedia interaktif berupa autoplay, dan (3) kelas virtual online edmodo. Pada produk buku cetak pembelajaran sosio antropologi olahraga terdiri dari beberapa materi antara lain (1) bab 1 rancangan pembelajaran blended learning, (2) bab II konsep dasar sosiologi dan antropologi olahraga, (3) bab III proses sosial dan interaksi sosial dalam olahraga, (4) bab IV kepemimpinan dalam olahraga, (5) bab V penyimpangan sosial dan agresi dalam olahraga, (6) bab VI hubungan olahraga dengan politik, (7) bab VII hubungan media massa dengan olahraga, (8) hubungan ekonomi dengan olahraga, dan (9) isu gender dalam olahraga. Pada buku cetak pembelajaran Sosio Antropologi Olahraga mempunyai kelebihan yaitu terdapat $Q R$ Barcode untuk mengakses video pembelajaran yang sesuai dengan materi yang ada di buku. Pada bagian buku terdapat soal evaluasi dengan bentuk pilihan ganda yang bertujuan untuk mengukur ketercapaian hasil belajar mahasiswa pada pembelajaran Sosio Antropologi Olahraga. Sumber belajar dengan menggunakan buku pembelajaran sangatlah efektif dalam meningkatkan ketercapaian hasil belajar (Robinson, Fischer, Willey, Hilton, 2014). Penelitian dari (Lin, 2017) menjelaskan bahwa manfaat dari buku teks sebagai sumber pembelajaran sangat beragam diantaranya 53,33\% responded menyatakan sangat setuju bahwa belajar menggunakan buku dapat menambah pemahaman, $16,67 \%$ setuju, 47,78\% evaluasi pembelajaran dapat meningkat dengan menggunakan buku, $51,11 \%$ dievaluasi sebagai bahan pembelajaran yang efektif dan 1,11\% kurang setuju.

Peneliti juga mengembangkan produk pembelajaran secara offline Sosio Antropologi Olaharga berbasis blended learning yang dikemas dengan menggunakan multimedia interaktif berupa autoplay. Materi produk pembelajaran multimedia interaktif autoplay terdiri dari menu (1) pengantar, (2) profil pengembang, (3) buku elektronik, (4) proes dan interaksi sosial, (5) kepemimpinan olahraga, (6) penyimpangan olahraga, (7) isu gender olahraga, (8) quiz, dan (9) edmodo. Keunggulan dari produk pembelajaran Sosio Antropologi Olahraga berbasis blended learning yang dikemas menggunakan multimedia interaktif autoplay yaitu terdapat buku pembelajaran sosio antropologi olahraga berbentuk flipbook. Multimedia yang menarik yang berisikan materi pembelajaran Sosio Antropologi Olahraga dan memuat beberapa video pembelajaran dapat membuat motivasi mahasiswa meningkat dalam menganalisis masalah pada saat proses pembelajaran. Terdapat juga soal evaluasi di dalam aplikasi autoplay yang hasilnya dapat langsung diketahui setelah soal selesai dikerjakan. Pembelajaran yang dibantu multimedia interaktif telah menjadi bentuk standar pendidikan pada masa sekarang. Dalam dunia olahraga, materi multimedia interaktif telah digunakan untuk mengajarkan aspek praktis dari kursus, yaitu keterampilan dalam bergerak dasar atau manipulatif (Leser, Baca, Uhlig, 2011). (Pill, Penney, \& Swabey, 2012) menjelaskan bahwa dengan adanya video di dalam multimedia interaktif dapat membantu meningkatkan motivasi dan hsil belajar serta meningkatkan kemampuan peserta didik dalam memahami suatu materi. Metode pembelajaran dengan pendekatan multimedia lebih sesuai dalam memperhatikan pencapaian tujuan pembelajaran (Sharma, 2013). Keterlibatan peserta didik dalam berdiskusi di dalam proses pembelajaran jauh lebih tinggi dengan bantuan multimedia interaktif (Yueh, Lin, Huang, Sheen, 2012).

Selain produk pengembangan berupa buku cetak dan multimedia interaktif autoplay, peneliti juga memanfaatkan media pembelajaran online melalui kelas virtual edmodo sebagai alternatif sumber belajar bagi mahasiswa yang bisa diakses kapan saja dan dimana saja selama tersambung koneksi internet. Pemanfaatan kelas virtual edmodo sebagai alternatif sumber belajar online difokuskan kepada pemberian materi yang akan dibahas pada proses pembelajaran selanjutnya. Kelebihan fitur kelas virtual edmodo terdiri dari (1) profil yang dapat diubah sendiri, (2) media untuk berbagi dokumen/file tugas kepada pengguna yang lain baik pendidik maupun pebelajar, (3) proses interaksi yang lebih sistematis antara pendidik dan pebelejar (peserta didik). Dengan memanfaatkan edmodo sebagai salah satu sumber belajar serta meningkatkan hasil belajar karena proses pembelajarannya tidak terikan dengan waktu. Edmodo memberikan kesempatan untuk membuat ruang kelas virtual, pendidik menciptakan hubungan antara pembelajaran teoretis dan praktis dalam membangun komunikasi serta kolaborasi (Ekici, 2017). Pendapat lain dari (Gay, 2017) pengguna edmodo berhasil memfasilitasi partisipasi peserta didik dalam diskusi serta tugas online dan juga meningkatkan minat serta motivasi peserta didik dalam upaya meningkatkan keterampilan. Menurut (Clark \& Mayer, 2008), pembelajaran online ditujukan untuk membantu peserta didik mencapai tujuan belajar. Lebih lanjut, menurut (Sujadi, Kurniasih, \& Subanti, 2017) menunjukkan bahwa pembelajaran dengan edmodo efektif untuk meningkatkan tingkat berpikir peserta didik.

Pembelajaran Sosio Antropologi Olahraga di Jurusan Pendidikan Jasmani dan Kesehatan Fakultas Ilmu Keolahragaan Universitas Negeri Malang mayoritas menggunakan teori di kelas dan melakukan pembelajaran di lapangan hanya pada pertemuan terakhir matakuliah, namun kendala yang biasanya terjadi di dalam proses pembelajaran yaitu mahasiswa sulit mendapatkan sumber belajar cetak yang terbaru maupun sumber belajar offline. Jadi, sebagian besar mahasiswa masih mencari sumber-sumber belajar yang mereka butuhkan melalui internet dari Wordpress dan BlogSpot. Hasil penelitian (Dikshit, Garg, Panda, 2013) menunjukkan bahwa aspek pedagogi dengan memanfaatkan multimedia interaktif ternyata efektif dalam mendukung kegiatan pembelajaran, berbagai kegiatan belajar juga disampaikan melalui buku cetak dengan pendekatan tatap muka serta materi juga disajikan melalui web dengan dukungan pendekatan online.

Keseluruhan hasil penelitian ini yaitu dengan menerapkan model pembelajaran Sosio Antropologi Olahraga berbasis blended learning terbukti dapat meningkatkan motivasi, minat, dan hasil belajar mahasiswa dalam pembelajaran Sosio Antropologi Olahraga yang mencakup aspek efektivitas, efisiensi, dan daya tarik pembelajaran. Pendapat tersebut sejalan dengan hasil penelitian dari (Ceylan \& Kesici, 2017) yang menyatakan bahwa blended learning memberikan hasil belajar yang lebih efektif melalui pembelajaran teknologi berbasis web yang berkembang saat ini pada lingkungan belajar. Penelitian lain 
dari (Obiedat, Eddeen, Harfoushi, Hamarsheh, Koury, Alassaf, 2014) menunjukkan bahwa ada pengaruh yang signifikan dan positif dari pembelajaran dengan pendekatan blended learning pada pencapaian nilai akademik mahasiswa. (Karamizadeh, Zarifsanayei, Faghihi, Mohammadi, Habibi, 2012) menyatakan bahwa blended learning secara efisiensi mampu menciptakan fleksibilitas waktu, tempat dan percepatan akses belajar serta memberikan kemandirian bagi pebelajar yang konsisten dengan fitur-fitur yang menarik. Selanjutnya, hasil penelitian lain dari (Wichadee, 2017) menunjukkan bahwa pembelajaran berbasis blended lebih efektif dari pembelajaran tradisioanal baik kemampuan lisan maupun motivasi.

\section{SIMPULAN}

Pengembangan pembelajaran berbasis blended learning pada matakuliah sosio antropologi olahraga untuk mahasiswa pendidikan jasmani dan kesehatan Universitas Negeri Malang masih dilakukan dengan metode tatap muka dan pembelajaran dilakukan konvensional dalam proses mempelajari materi-materi di setiap pertemuan. Proses pembelajaran yang sesuai untuk dilakukan yaitu menggabungkan pembelajaran dengan teknologi saat ini yang membagi waktu proses pembelajaran melalui tatap muka, offline, online dengan tujuan semua ranah kompetensi dapat tercapai secara maksimal.

Keseluruhan hasil penelitian ini menerapkan model pembelajaran yang menggunakan blended learning yang mengombinasi antara tatap muka menggunakan buku cetak yang dilengkapi QR barcode, offline menggunakan multimedia interaktif, dan online menggunakan jejaring sosial edmodo. Blended learning terbukti dapat meningkatkan motivasi, minat, serta hasil belajar mahasiswa pendidikan jasmani dan kesehatan dalam pembelajaran Sosio Antropologi Olahraga Pendidikan Jasmani dan Kesehatan yang mencakup aspek efektivitas, efisiensi, dan daya tarik pembelajaran. Hasil penelitian ini sejalan dengan (Ceylan \& Kesici, 2017) yang menjelaskan blended learning memberikan hasil belajar yang efektif dan efisien melalui proses pembelajaran teknologi berbasis web pada lingkungan belajar. Lebih lanjut, (Obiedat, Eddeen, Harfoushi Hamarsheh, Koury, Alassaf, 2014) memaparkan bahwa terdapat pengaruh yang signifikasi dan positif dari pembelajaran dengan pendekatan blended learning pada pencapaian hasil belajar mahasiswa.

Blended learning secara efisien mampu menciptakan fleksibilitas waktu, tempat dan percepatan akses belajar serta memberikan kemandirian bagi pebelajar dan pendidik yang konsisten dengan fitur-fitur yang menarik (Karamizadeh, Zarifsanayei, Faghihi, Mohammadi, \& Habibi, 2012). (Wichadee, 2017) menjelaskan bahwa pembelajaran blended lebih efektif dari pembelajaran konvensional baik dari aspek lisan serta motivasi. Berdasarkan hasil penelitian dan pendapat yang telah dijelaskan diatas maka dapat disimpulkan bahwa proses pembelajaran dengan menggunakan pendekatan blended learning mengalami peningkatan hasil belajar baik dari nilai, penggunaan waktu, dan kemenarikan.

Meskipun hasil yang didapatkan baik (layak) dari produk pengembangan blended learning Sosio Antropologi Olahraga untuk mahasiswa Pendidikan Jasmani dan Kesehatan Universitas Negeri Malang yang telah dikembangkan dengan landasan sebagai berikut: (1) acuan dasar dari pengembangan produk ini adalah hasil analisis kebutuhan atau kondisi pada saat sekarang dan apabila pengembang selanjutnya ingin mengembangkan produk dengan konteks sejenis atau lainnya agar memperhatikan kembali kondisi pada saat itu, (2) sebelum mengembangkan produk seharusnya memperhatikan materi yang akan diuji cobakan agar produk yang dihasilkan tepat ke sasaran, (3) penelitian dan pengembangan dengan pendekatan menggunakan blended learning harus dapat lebih memperhatikan kondisi yang memengaruhi diantaranya adalah hasil dari kompetensi, tujuan pembelajaran, tempat, kemampuan pendidik (dosen), kurikulum yang dipakai untuk rujukan, serta kesediaan sumber daya sebagai pendukung pembelajaran, (4) pada uji efektivitas selanjutnya hendaknya menggunakan kelompok pembanding agar produk yang dihasilkan dapat lebih bermakna dan berfungsi dalam meningkatkan hasil belajar.

Berdasarkan pendapat yang telah dijelaskan maka dapat disimpulkan bahwa proses pembelajaran dengan menggunakan pendekatan blended learning dianggap lebih dapat dalam mencapai tujuan pembelajaran secara proporsional dari segi efektif, efisiensi, dan kemenarikan. Selain proses pembelajaran yang tidak terikat oleh waktu, interaksi antara pebelajar/peserta didik dan pendidik (dosen) juga dapat lebih dalam lagi sehingga permasalahan pembelajaran pada tatap muka (face to face) dapat didiskusikan dalam kelas online (edmodo), tampilan sumber belajar offline (multimedia interaktif) juga memberi semangat dan kemudahan untuk pebelajar/peserta didik karena pengemasan dalam menyampaikan materi menjadi lebih menarik karena dikemas menjadi lebih interaktif lagi. Keseluruhan komponen-komponen yang saling mendukung dalam pemanfaatan media, tatap muka (face to face), offline dan online guna mendukung proses pembelajaran menjadikan model blended learning sangat efektif, efisien, dan memiliki daya tarik tersendiri untuk meningkatkan hasil belajar pebelajar/peserta didik, serta produk yang dihasilkan dalam penelitian pengembangan ini mendukung percepatan sebuah akses informasi pembelajaran antara pebelajar dengan pebelajar, pebelajar/peserta didik dan pendidik menggunakan sumber belajar sehingga didapatkan hasil belajar yang baik dari penerapan pembelajaran blended learning Sosio Antropologi Olahraga untuk mahasiswa Penididikan Jasmani dan Kesehatan Universitas Negeri Malang.

\section{DAFTAR RUJUKAN}

Akbar, S. (2013). Instrumen Perangkat Pembelajaran. Bandung: Rosdakarya.

Berlex, D. M. (2008). Design Without Make. Challenging the Conventional Approach Teaching and Learning in a Design and Technology Classroom. International Journal Design Education, 18, 119-133.

Ceylan, V. K., \& Kesici, A. (2017). Effect of Blended Learning to Academic Achievement. Journal of Human Sciences, 14(1), 308-320. 
Clark, R. C. \& Mayer, R. (2008). E-Learning and The Science of Instruction: Proven Guidelines for Consumers anda Designer of Multimedia Learning.

Degeng, N. (2013). Ilmu Pembelajaran; Klasifikasi Variabel untuk Pengembangan Teori dan Penelitian. Bandung: Kalam Hidup Arasmedia.

Dikshit, J., Garg, S., \& Panda, S. (2013). Pedagogic Effectiveness of Print, Interactive Multimedia, and Online Resources: A Case Study of IGNOU. International Journal of Instruction, 6(2), 193-210.

Dwiyogo, W. D. (2016). Pembelajaran Berbasis Blended Learning. Malang: Wineka Media.

Ekici, D. (2017). The Use of Edmodo In Creating an Online Learning Community of Practice for Learning to Teach Science. Malaysian Online Journal of Educational Sciences, 5(2), 91-106.

Gay, E., S. N. (2017). The Effectiveness of Using Edmodo in Enhancing Students' Outcomes in Advance Writing Course of The Fifth Semester at FIP - UMMU. Journal of English Education, 2(1), 1-11.

Karamizadeh, Z., Zarifsanayei, N., Faghihi, A. A., Mohammadi, H., \& Habibi, H. (2012). The Study of Effectiveness of Blended Learning Approach for Medical Training Courses. Iran Red Crescent Med Journal, 14(1),41-44.

Leser, R., Baca, A., \& Uhlig, J. (2011). Effectiveness of Multimedia-Supported Educational in Practical Sports Courses. Journal of Sport Science \& Medicine, 10(1), 84.

Lin, Y. W., D. (2017). The Effect of Blended Learning in Mathematics Course. Eurasian Journal of Mathematics, Science \& Technology Education, 13(3).

Mazoloumiyan, S., Shobeiri, S. M., Farajollahi, M., Mohamadi, M. (2012). Blended Learning: A New Approach to Environmental Education for Iran High School. Procedia Social and Behavioral Sciences, 47: 1216-1.

Obiedat, R., Eddeen, L.N., Harfoushi O., Hamarsheh, M.A., Koury, A., \& Alassaf, N. (2014). Effect of Blended-Learning on Academic Achievement of Students in the University of Jordan. International Journal of Emerging Technologies in Learning, 9(2), 37.

Pill, S., Penney, D., \& Swabey, K. (2012). Rethinking Sport Teaching in Physical Education: A Case Study of Research Based Innovation in Teacher Education. Australian Journal of Teacher Education, 37(8), 118.

Reigeluth, C. M. (2012). Instructional Theory and Technology for the New Paradigm of Education. Revista de Educacion a Distancia, 32, 1-18.

Robinson, T. J., Fischer, L., Willey, D., Hilton, H. (2014). The Impact of Open Textbooks on Secondary Science Learning Outcomes. Educational Researcher. Educational Researcher, 43(7), 34.

Saba, A. (2009). Benefits of Technology Integration in Education. Boise State University, EdTech 501, 1.

Sharma, K. \&. (2011). Use of Information Technology in Physical Education and Sport. Physical Education and Sport, 2(4), 1-6.

Sharma, P. (2013). Role of Interactive Multimedia for Enhancing Students' Achievement and Retention. International Women Online Journal of Distance Education, 2(3), 12-2.

Sugiyono. (2016). Metode Penelitian dan Pengembangan. Bandung: Alfabeta.

Sujadi, I., Kurniasih, N., \& Subanti, S. (2017). The Effectiveness of Learning Material with Edmodo to Enhance the Level of Student's Probabilistic Thinking. Mathematics, Science, and Computer Science Education, 1848(1).

Sutopo, A. H. (2012). Teknologi Informasi dan Komunikasi dalam Pendidikan. Yogyakarta: Graha Ilmu.

Vaughan, N. (2014). Student Engagement and Blended Learning: Making the Assesment Connection. Education Sciences, 4(4), 247.

Vernadakis, N. Giannousi, M. Derri, V. Michalopoulos, M. \& Kioumourtzoglou, E. (2012). The impact of Blended and Traditional Instruction in Students' Performance. SciVerse Science Direct, Procedia Technology, 1, 439 - 4, 1.

Wichadee, S. (2017). A Development of the Blended Learning Model Using Edmodo for Maximizing Students' Oral Proficiency and Motivation. International Journal of Emerging Technologies in Learning, 12(2), 137.

Yueh, H. P., Lin, W., Huang, J. Y., \& Sheen, H. J. (2012). Effect of Student Engagement on Multimedia-Assisted Instruction. Knowledge Management \& E-Learning: An International Journal, 4(3), 347. 